Pak. j. sci. ind. res. Ser. A: phys. sci. 2021 64A(1) 26-34

\title{
Characterization of Cleaning Potential of Khokhar-Bala, Punjab (Pakistan) Coal and Simulation-Based Study for Identification of Best Strategy for its Cleaning
}

\author{
Muhammad Shahzad*, Syed Mahmood Arshad, Zulfiqar Ali, \\ Rana Ahmad Ali and Hamza Shabeer \\ Mining Engineering Department, University of Engineering and Technology, Lahore, Pakistan
}

(received September 4, 2019; revised January 6, 2020; accepted January 27, 2020)

\begin{abstract}
This study involves the characterization of Khokhar-Bala coal of Punjab (Pakistan) coal field to establish its particle distribution data for size, density and floatability through sizing, float-sink tests and release analysis. Khokhar Bala coal contains high amounts of unwanted impurities like ash (35.22\%) and sulphur (8.38\%). Over $93 \%$ of its mass consists of $+1.00 \mathrm{~mm}$ particles, when run-of-mine coal is crushed to $38 \mathrm{~mm}$. Washability curves, degrees of washing and the S-values show that the coarser fractions $(-38+25 \mathrm{~mm} ;-25+13.33 \mathrm{~mm} ;-13.33+3.35 \mathrm{~mm})$ are extremely difficult to clean, whereas the cleaning potential is high for size fractions $-3.35+1.00 \mathrm{~mm}$ (moderately difficult) and $-1.00+0.15 \mathrm{~mm}$ (relatively easy). Modelling and simulation of several processing configurations indicate that at $16 \%$ target ash content, dense medium cyclone treating $38 \times 1 \mathrm{~mm}$ coal particles will provide the maximum clean yield of $37.39 \%$ with sulphur content of $4.80 \%$.
\end{abstract}

Keywords: characterization, Punjab coal, washability, float-sink, release analysis, simulation

\section{Introduction}

Coal is a complex heterogeneous mixture of organic and inorganic constituents (Shahzad et al., 2016; Ural, 2007), which is primarily used in electricity generation, cement manufacturing and steel making. The other important uses of coal include coal-derived fuels and chemicals (Osborne and Gupta, 2013). The inorganic constituents, also called mineral matter are the noncombustible materials such as shale, clay, pyrite, quartz, carbonate, etc. These materials are unwanted impurities that act as diluent which result in reduced heating value and increase transportation cost of unit coal mass (Ali, 2012; Ward, 2002). These impurities also affect the suitability of coal for its use in formation of coke, synthetic fuels and petrochemicals described by Ali (2012). Moreover, coals containing sulphur and sulphurbearing minerals like pyrite produce sulphur dioxide during the burning of coal which cause harmful impacts on the environment and human health (Oteyaka et al., 2008).

To overcome the problems caused by the non-combustible mineral matter in coal, it is generally required to reduce the amount of these materials to the limits dictated by end-user by employing coal preparation

*Author for correspondence;

E-mail: m.shahzad87@uet.edu.pk techniques. When designing a coal preparation plant, generation of extensive laboratory data related to coal characteristics is usually required. This generally involves the determination of mineral matter distribution and washability characteristics of coal at various size levels. After generation of such data, modelling and simulation work is usually performed to find the most appropriate processing circuit that provides maximum yield at the target impurity level.

Various simulation programs are available to design and optimize coal processing circuits including MODSIM (King, 1999), CPDES (Yaqun et al., 2002), SUI-SIM (Huang et al., 2008), and LIMN (Noble et al., 2014; Bergh et al., 2013; Hand and Wiseman, 2008) etc. LIMN is a spread sheet-based flowsheet simulation software package which has significantly contributed in the coal preparation industry especially in south Africa and Australia due to its ability to readily handle particulate solid flow and separation calculations. The advanced features in LIMN can be used for circuit optimization, equipment selection, evaluation of operational configurations, modelling of complicated processing circuits and to produce simulations for plant design and performance evaluations (Noble et al., 2014).

Punjab province of Pakistan possesses the in-situ coal resources of 588 million tons (Scott et al., 2013). These 
resources are found in two coal horizons in the upper Indus Basin (salt range) and the Surghar range; extending from Joggi Tilla (Jhelum) to Makerwal covering more than $250 \mathrm{~km}$ (Fig. 1) (Shah, 2009). Punjab coal is characterized by high amounts of ash-forming and sulphur bearing minerals which restrict its consumption to brick making industry only (Shahzad et al., 2014) whereas, high quality coal is imported to fulfill the energy needs of power, cement and other industries of Punjab. To utilize indigenous coal resources in these industries, it is essential to upgrade their quality by reducing the amount of ash-forming and sulphur-bearing minerals to an acceptable level.

Previously, some studies were performed to establish washability characteristics and flotation response of Punjab coal, and to evaluate its cleaning potential by gravity separation and froth flotation techniques (Shahzad and Ali, 2019; Shahzad and Ali, 2018a; Shahzad et al., 2017; 2015) but no systematic study was conducted to design a coal processing circuit. At present, there is not a single State-of-the-art coal preparation plant in operation in Punjab province to improve the quality of indigenous coal to make it suitable for cement and power industries of the province which limit coal ash and sulphur at $16.0 \%$ and $1.0 \%$, respectively. This research work was conducted with intention to address this deficiency. The basic objective of this research work is to characterise the coal in a systematic manner for establishing its particle distributions for size, density and floatability. The main aim is to evaluate different processing options by running simulations using limn software to identify the best processing strategy.

\section{Materials and Methods}

Gross coal sample amounting over $345 \mathrm{Kg}$ was collected from the stockpiles of Geo-Mineral Associates coal mines located near Khokhar Bala village in Dalwal zone of salt range coalfield of Punjab in accordance to ASTM standards (ASTM D-6883 and ASTM D-2234) and the method described elsewhere (Shahzad et al., 2016). Gross coal sample was crushed by using Blake type jaw crusher set at $25-38 \mathrm{~mm}$. The crushed product was thoroughly mixed and divided into four parts. One part was prepared following ASTM D-2013 to obtain an analytical sample for proximate analysis and determination of forms of sulfur. The proximate properties were measured as per ASTM D-3172, -3173, -3174, and -3175 , whereas ASTM D-2492 were followed for the determination of forms of sulphur.
The other three parts were combined and sieved at $25.00,13.33,3.35,1.00$, and $0.15 \mathrm{~mm}$ aperture sizes. The resultant fractions were divided separately into two halves; one half of each fraction was prepared to determine its ash and sulphur contents whereas, the other halves were separately subjected to float-sink tests except that of $-0.25 \mathrm{~mm}$ which was used to perform Dell release analysis. Total 10 dense mediums having specific gravities of $1.30,1.35,1.40,1.45,1.50,1.55$, $1.60,1.65,1.70$ and 1.80 were utilised for each floatsink test. Organic liquids (petroleum spirit, carbon tetra chloride, bromo form) were used to prepare heavy mediums for $1.00 \times 0.25 \mathrm{~mm}$ size fraction, while, aqueous solution of zinc chloride was used for the remaining fractions. In Dell release analysis, kerosene

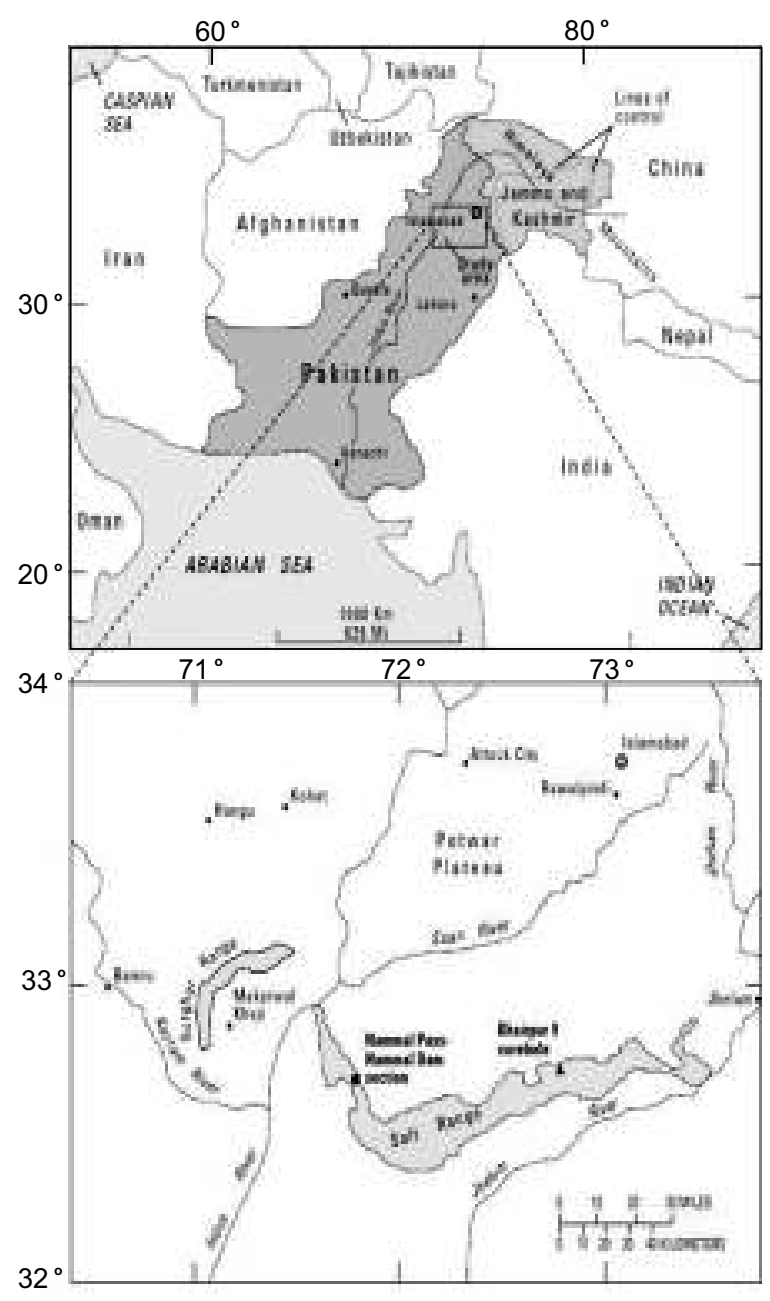

Fig. 1. The coal horizons of Punjab coalfield; salt range and Surghar range (Bybell and SelfTrail, 2007). 
oil and methyl iso-butyl carbinol (MIBC) were used as collector and frother in the range of $400 \mathrm{~g} / \mathrm{t}$ and $100 \mathrm{~g} / \mathrm{t}$ respectively. The mixing and conditioning time was kept at five minutes each. The solid percentage and impeller speed were maintained at $15 \%$ and $1300 \mathrm{rpm}$ respectively whereas, $\mathrm{pH}$ was kept natural. The fractions obtained from float-sink and release tests were analysed for ash and sulfur as per ASTM D-3174 and ASTM D3177 , respectively.

\section{Results and Discussion}

Proximate and sieve analysis. Proximate analysis performed on raw coal revealed that Khokhar Bala coal contained low inherent moisture $(2.20 \%)$, high ash $(35.22 \%)$, high volatile matter $(33.70 \%)$ and low fixed carbon $(28.87 \%)$. It contained very high amount of total sulphur of $8.38 \%$. Total sulphur comprised of $0.89 \%$ organic, $6.34 \%$ pyritic and $1.15 \%$ sulphate components. The results of sieve analysis and proximate properties of each size fraction are presented in Fig. 2. The sizing analysis showed that coarse fraction $(+25 \mathrm{~mm})$ constituted nearly half of the total feed mass whereas, over $93 \%$ of coal consisted of $+1.00 \mathrm{~mm}$ particles. Typically, $38 \times 1 \mathrm{~mm}$ coal particles are cleaned by either dense medium cyclones or jigs throughout the world.

The proximate properties of various size fractions revealed that ash contents, in general, increased with decreasing particle size. This trend may be due to the presence of ash forming minerals in the form of amalgamates of fine particles and the nodules of variable sizes. Crushing broke the cementing forces which

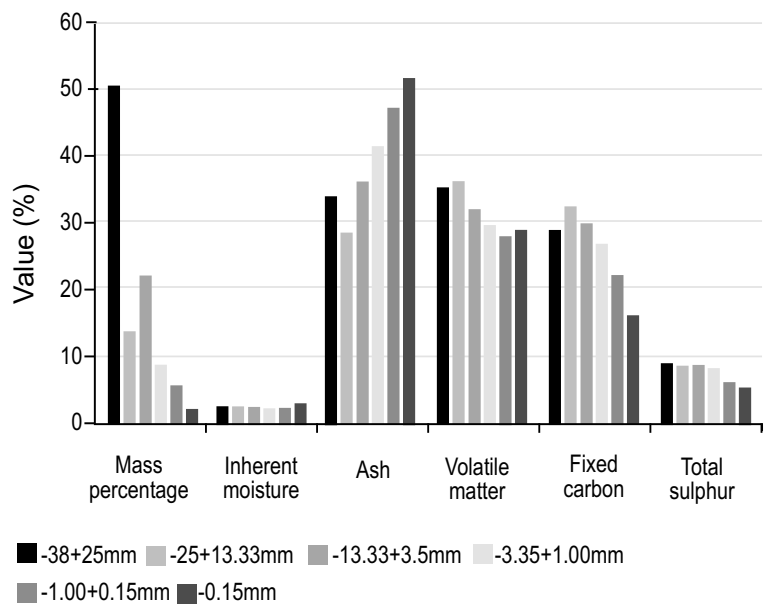

Fig. 2. Sizing characteristics of Khokhar Bala, Punjab coal. trickled down these fine particles and nodules to finer size fractions (Shahzad et al., 2016). The total sulphur content remained nearly the same $(8.29-8.75 \%)$ for $+1.00 \mathrm{~mm}$ size fractions whereas, finer fractions exhibited relatively lower sulphur values ranging between $5.59 \%$ and $5.99 \%$. This behaviour may be associated with high amounts of pyrite present in Punjab coal. Pyrite is relatively hard and does not break easily into fine particles by crushing forces, resulting in its higher amounts in the coarser fractions. Since the ultrafine fraction $(-0.15 \mathrm{~mm})$ constituted a minute proportion (1.55\%) of feed coal with the highest amount of ash content (51.74\%). It can be discarded directly into tailings without processing.

Washability analysis. The washability curves plotted from the float-sink data of $-38+25 \mathrm{~mm},-25+13.33$ $\mathrm{mm},-13.33+3.35 \mathrm{~mm},-3.35+1.00 \mathrm{~mm}$ and $-1.00+0.15$ $\mathrm{mm}$ are presented in Fig. 3-7, respectively. The washability curves predict the theoretical yield of clean coal along with operating specific gravity of separation and the amount of near-gravity material at the specified ash/sulphur content. In addition, these curves also predict the yield and quality of tailings/waste product at the same specific gravity of separation (Gupta and Yan, 2006). At $16 \%$ limit ash content, the yield and sulphur contents of clean coal, specific gravity of operation,

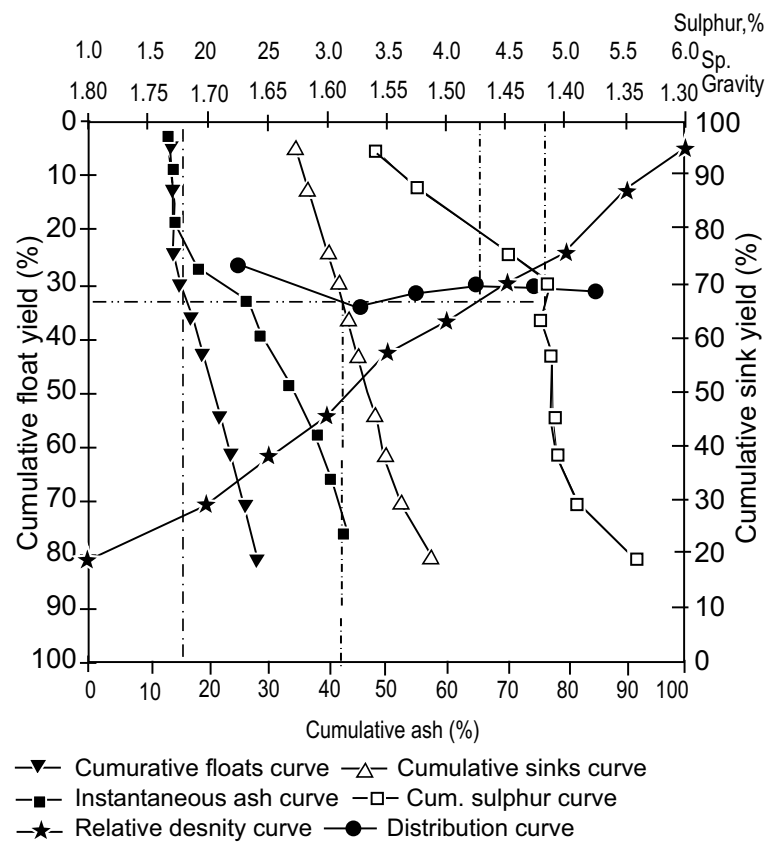

Fig. 3. Washability characteristic curves of size fraction $38 \times 25 \mathrm{~mm}$. 
amount of near gravity material and yield and quality of tailings product are presented in Table 1 along with the feed ash and sulfur contents for the above-mentioned size fractions of Khokhar-Bala, Punjab coal.

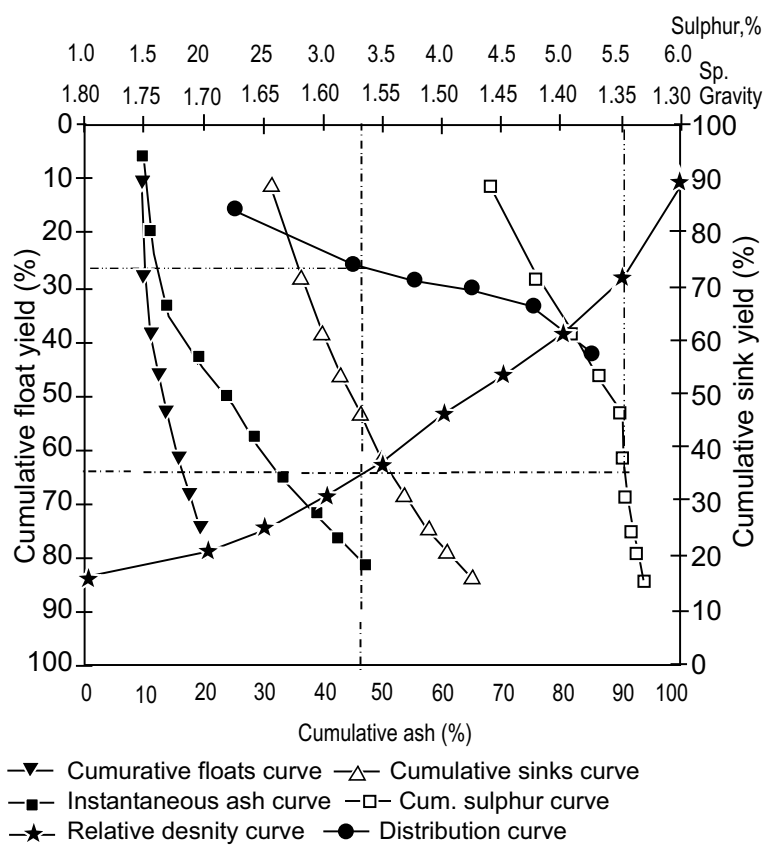

Fig. 4. Washability characteristic curves of size fraction $25 \times 13 \mathrm{~mm}$.

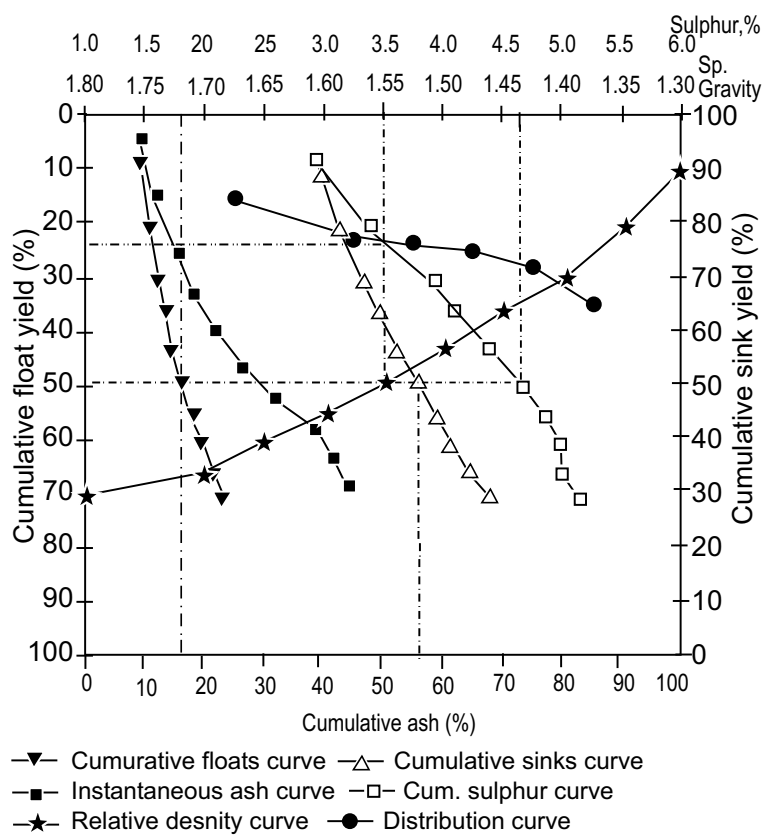

Fig. 5. Washability characteristic curves of size fraction $13 \times 3.35 \mathrm{~mm}$.
At $16 \%$ target ash, the size fractions $-38+25 \mathrm{~mm}$ and $-25+13.33 \mathrm{~mm}$ gave the minimum and maximum yields of clean coal, respectively. The maximum yield of $-25+13.33 \mathrm{~mm}$ size fraction could be due to its minimum

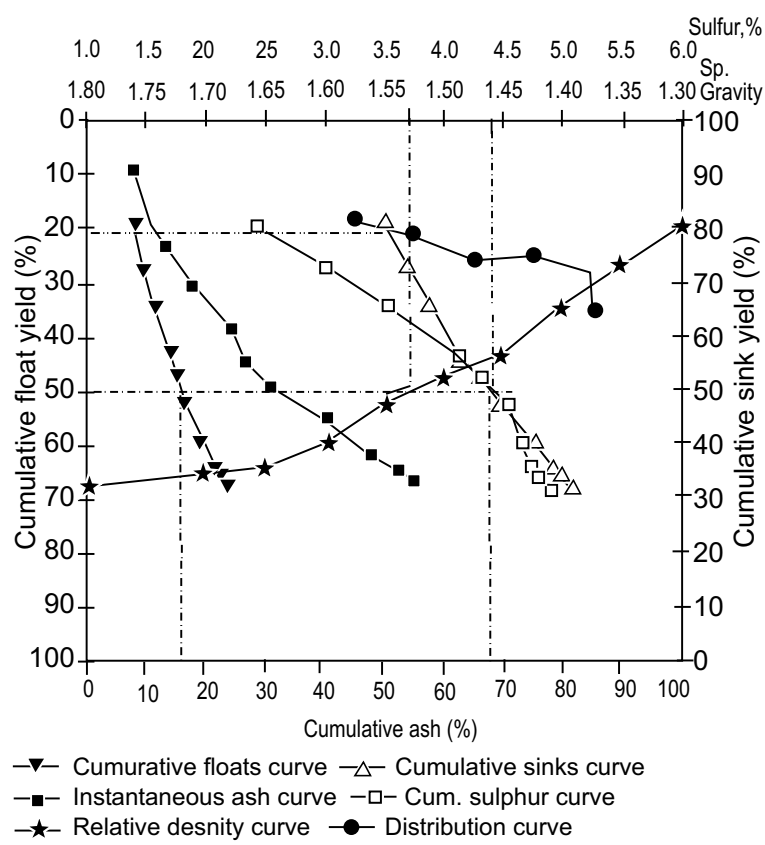

Fig. 6. Washability characteristic curves of size fraction $3.35 \times 1.00 \mathrm{~mm}$

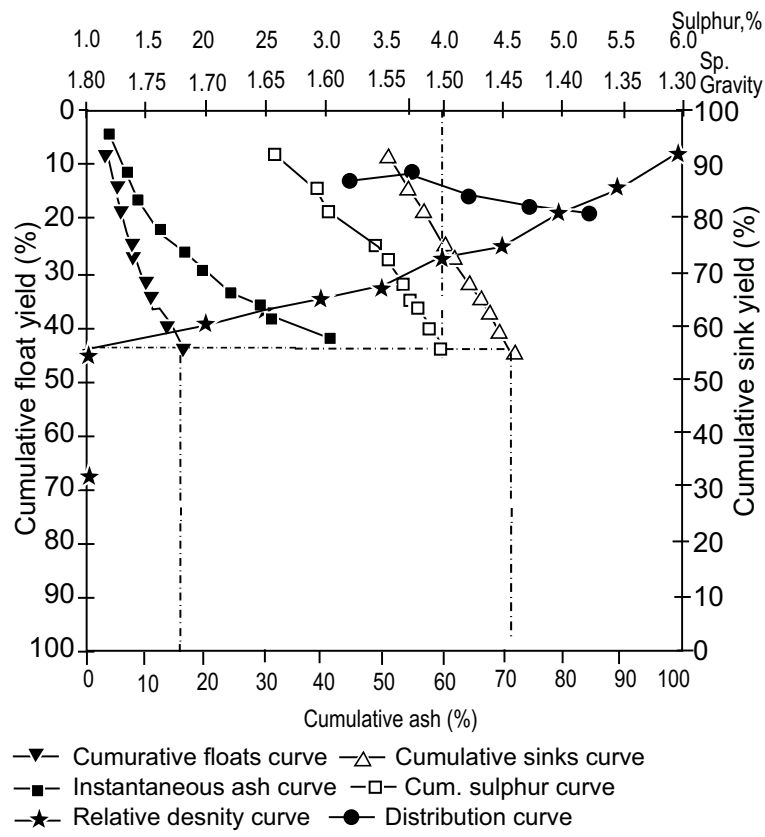

Fig. 7. Washability characteristic curves of size fraction $1.00 \times 0.15 \mathrm{~mm}$. 
feed ash content and relatively better liberation of coal particles whereas the minimum yield of $-38+25 \mathrm{~mm}$ may be attributed to the poor liberation of ash-forming minerals in the coarser particles. The clean coal yield remained in the range of $43-49 \%$ for the remaining finer size fractions despite increasing feed ash content with decreasing particle size. This indicates that liberation of ash-forming minerals improves with decreasing particle size, especially below $25 \mathrm{~mm}$.

On the other hand, sulphur bearing minerals exhibited different behaviour as indicated by the amount of clean coal sulphur at $16 \%$ ash content (Table 1). The coarsest and the finest fractions provided the minimum reduction of sulphur $(\approx 33 \%)$ whereas, the sulphfur reduction values $(\approx 43-47 \%)$ were higher for the middle fractions. The lower reduction in the coarsest fraction may be attributed to the less liberation of sulphur-bearing minerals whereas, the presence of sulphur-bearing minerals within coal matrix in the form of finely disseminated particles may be the cause of lower reduction in the finest size fraction.

Conventionally, the ease of coal washing is indicated by the shape of instantaneous ash curve also called primary washability curve. More it close to the shape of letter L, easier it will be to wash the coal (Shahzad et al., 2015; Lin et al., 1999; Meyers et al., 1992). The shape of primary washability curves for all size fractions of Khokhar-Bala coal was found nearly identical and far away from the shape of letter L. However, the fractions finer than $3.35 \mathrm{~mm}$ size produced relatively better primary washability curves, indicating enhanced washability characteristics of finer coal particles.

Another method to describe the ease or difficulty of coal cleaning is by percentages of near gravity material $( \pm 0.1 \mathrm{SG})$ at the required specific gravity (Bird, 1931). The percentage of near gravity materials at various specific gravities of separation is typically represented by the distribution curve. The more the percentage of near-gravity material, the more difficult will be to clean the coal (Gupta and Yan, 2006). It was found that the amount of near-gravity material was decreased with decreasing particle size showing better washing characteristics of finer size fractions.

Recently, a simple method to quantify the degree of coal washing was proposed by Shahzad and Ali (2018b). They introduced a simple mathematical equation for estimating the degree of coal washing in percentage at various specific gravities of separation. The higher the degree of coal washing, the easier will be to clean the coal. They also proposed an index, termed as S-value to represent the washability characteristics of coal by a single number, the value of which ranges between 0 and 100 . The equations for degree of washing and Svalue proposed by them are reproduced here:

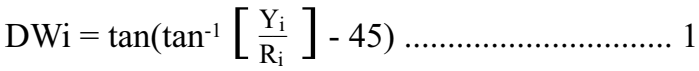

$$
\begin{aligned}
& \text { S-value }=\sqrt[4]{\left.\mathrm{DW}_{1.3} \times \mathrm{DW}_{1.4} \times \mathrm{DW}_{1.6} \times \mathrm{DW}_{1.8}\right)} \ldots \ldots . .2
\end{aligned}
$$

where:

DWi, Yi and Ri represent the degree of washing, cumulative float yield and cumulative ash recovery at 'i' specific gravity respectively. $\mathrm{DW}_{1.3}, \mathrm{DW}_{1.4}, \mathrm{DW}_{1.6}$ and $\mathrm{DW}_{1.8}$ are the degrees of washing at specific gravities of 1.3, 1.4, 1.6 and 1.8, respectively in percentages. They also proposed a classification system based on Svalue to determine the extent of coal cleaning. The degrees of washing and S-values were calculated for all size fractions of Khokhar-Bala coal which are provided in Table 2 .

The degrees of washing were found higher at lower specific gravities of separation for all size fractions

Table 1. Washability characteristics of various size fractions of Khokhar-Bala, Punjab coal at $16 \%$ target ash content of clean coal

\begin{tabular}{|c|c|c|c|c|c|c|c|c|c|}
\hline \multirow[t]{3}{*}{ Size fraction } & \multicolumn{2}{|c|}{ Feed coal } & \multicolumn{2}{|c|}{ Clean coal } & \multicolumn{3}{|c|}{ Tailings product } & \multirow{3}{*}{$\begin{array}{l}\text { Specific } \\
\text { gravity of } \\
\text { separation }\end{array}$} & \multirow{3}{*}{$\begin{array}{l}\text { Near gravity } \\
\text { material (\%) }\end{array}$} \\
\hline & Ash & Sulphur & Yield & Sulphur & Yield & Ash & Sulphur & & \\
\hline & & & & $(\%)$ & & & & & \\
\hline$-38+25$ & 33.78 & 8.57 & 33.07 & 4.82 & 66.93 & 42.55 & 10.43 & 1.47 & 30.30 \\
\hline$-25+13.33$ & 28.62 & 8.29 & 63.79 & 5.52 & 36.21 & 50.93 & 13.22 & 1.57 & 27.82 \\
\hline$-13.33+3.35$ & 36.00 & 8.75 & 48.78 & 4.62 & 51.22 & 55.09 & 12.69 & 1.55 & 24.40 \\
\hline$-3.35+1.00$ & 42.04 & 8.38 & 49.49 & 4.59 & 50.51 & 67.61 & 12.28 & 1.53 & 23.66 \\
\hline$-1.00+0.15$ & 47.35 & 5.99 & 43.42 & 4.00 & 56.58 & 71.41 & 7.52 & 1.80 & 7.76 \\
\hline
\end{tabular}


Table 2. Degree of washing and S-values for various size fractions of Khokhar-Bala coal

\begin{tabular}{llllll}
\hline \hline Specific gravity & $-38+25 \mathrm{~mm}$ & $-25+13.33 \mathrm{~mm}$ & $-13.33+3.35 \mathrm{~mm}$ & $-3.35+1.00 \mathrm{~mm}$ & $-1.00+0.15 \mathrm{~mm}$ \\
\hline 1.30 & 42.83 & 51.35 & 58.04 & 69.74 & 83.48 \\
1.35 & 41.57 & 49.18 & 53.27 & 62.08 & 79.27 \\
1.40 & 40.78 & 45.50 & 48.88 & 56.92 & 76.53 \\
1.45 & 38.51 & 41.18 & 45.93 & 49.43 & 71.34 \\
1.50 & 32.77 & 35.97 & 41.89 & 46.53 & 69.17 \\
1.55 & 28.15 & 29.93 & 37.98 & 42.85 & 63.84 \\
1.60 & 21.16 & 24.95 & 33.67 & 35.76 & 60.99 \\
1.65 & 17.08 & 20.20 & 29.44 & 31.73 & 58.17 \\
1.70 & 12.91 & 17.27 & 25.42 & 30.51 & 54.47 \\
1.80 & 9.01 & 13.56 & 22.25 & 28.31 & 48.07 \\
S-Value & 24.02 & 29.82 & 38.18 & 45.37 & 65.79 \\
Cleaning extent & Extremely & Difficult & Difficult & Moderately & Relatively easy \\
& difficult & & & difficult & C \\
\hline \hline
\end{tabular}

indicating higher cleaning extent at lower specific gravities of separation. The values of degree of washing increased with decreasing particle size, thus indicating improved washability characteristics of Khokhar-Bala coal with decreasing particle size. The same trend was also found for the S-value. The coal class and the cleaning extent were also determined for all size fractions based on S-value and the proposed classification. It was found that the coarsest size fraction was extremely difficult to clean and the middle fractions belonged to difficult to moderately difficult class of coal cleaning. The finest fraction was found to be relatively easy to clean.

Release analysis. The flotation response of ultrafine fraction $(-0.15 \mathrm{~mm})$ measured by release analysis is presented in Fig. 8 in the form of yield-ash and yieldsulphur curves. These curves specified that ultrafine fraction of Khokhar-Bala coal would be difficult to clean by froth flotation. It would be extremely difficult to produce clean coal having ash content below $16 \%$ ash limit. At $40 \%$ yield, a clean coal with ash content of $21.24 \%$ and sulphur content of $4.53 \%$ was obtained from a feed coal having ash and sulphur contents of $51.74 \%$ and $5.59 \%$, respectively. The yield-sulphur curve showed very low reduction in sulphur contents. This behaviour may be attributed to the high floatability of pyrite. Since, the ultrafine size fraction constitutes only $1.55 \%$ of the total coal mass and the cost of treating ultrafine coal by froth flotation is always higher, it will be the best to discard this size fraction directly into the waste/tailings product during coal preparation.
Modelling and simulation of processing circuits. Modern coal preparation plants typically involve four separate parallel processing circuits for treating coarse $(+50 \mathrm{~mm})$, small $(50 \times 1 \mathrm{~mm})$, fine $(1 \times 0.15 \mathrm{~mm})$ and ultrafine $(-0.15 \mathrm{~mm})$ coal (Luttrell et al., 2014). Dense medium baths, dense medium cyclones, and jigs are the most common choices for treating coarse coal. Nowadays, almost all the small coal is treated in the dense medium cyclones. Spirals, shaking tables, fluidized-bed separators and water-only cyclones are the available technologies for cleaning fine coal, while froth flotation is the only technique to clean ultrafine coal at the commercial level (Osborne, 2013).

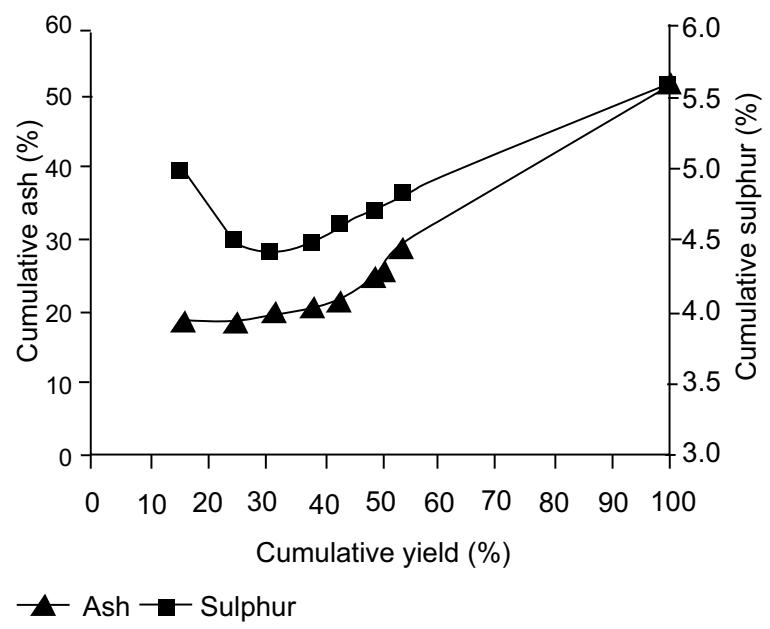

Fig. 8. Floatability response of size fraction -0.15 $\mathrm{mm}$. 
LIMN was used to model and simulate several types of coal processing circuits to generate simulated data for predicting clean coal yield, ash and sulphur. Since washability characteristics of Khokhar Bala coal dictated that it contained high percentage of near-gravity material, the water-based techniques would be less efficient. For coals containing higher amounts of near-gravity materials, dense medium separators are considered the best choice for their cleaning (Sripriya et al., 2007). Thus, three circuits based on dense medium separators along with one circuit based on water-based separators were modelled and simulated to generate clean coal data at specific gravity of separation ranging from 1.30 to 1.80. These circuits are described in Fig. 9-10. The simulated data generated for clean coal yield, ash and
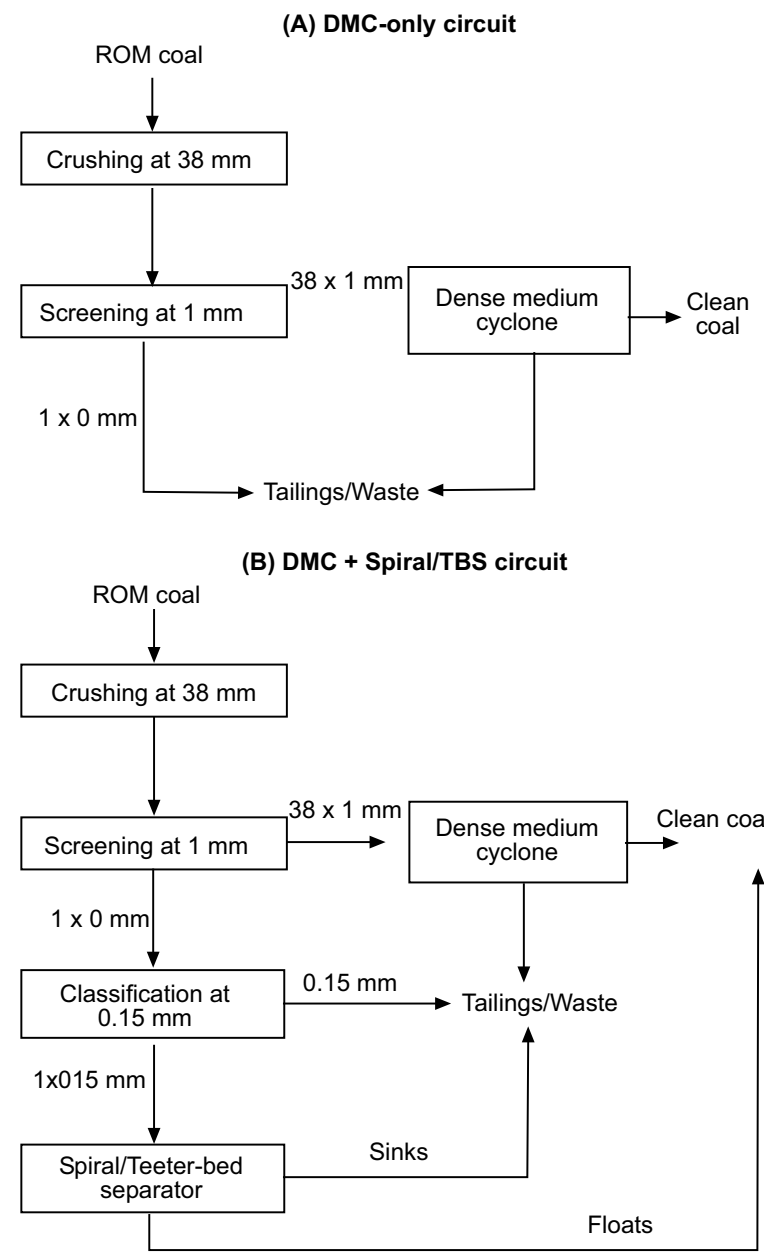

Fig. 9. Dense-medium based circuits: (A) Densemedium cyclone (DMC) only circuit, (B) Circuit consisting of dense medium cyclone and spiral separators.

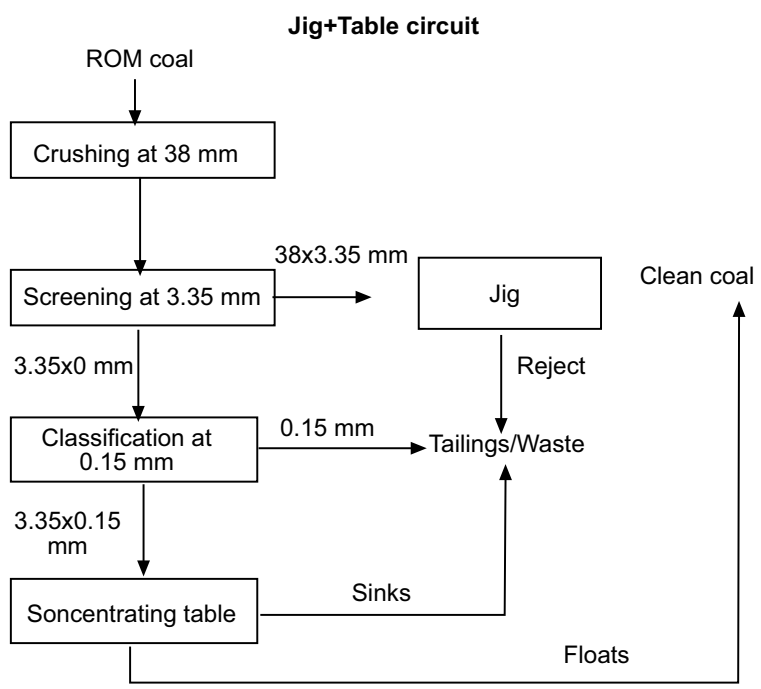

Fig. 10. Circuit consisting of water-based separators involving jig and concentrating Table.
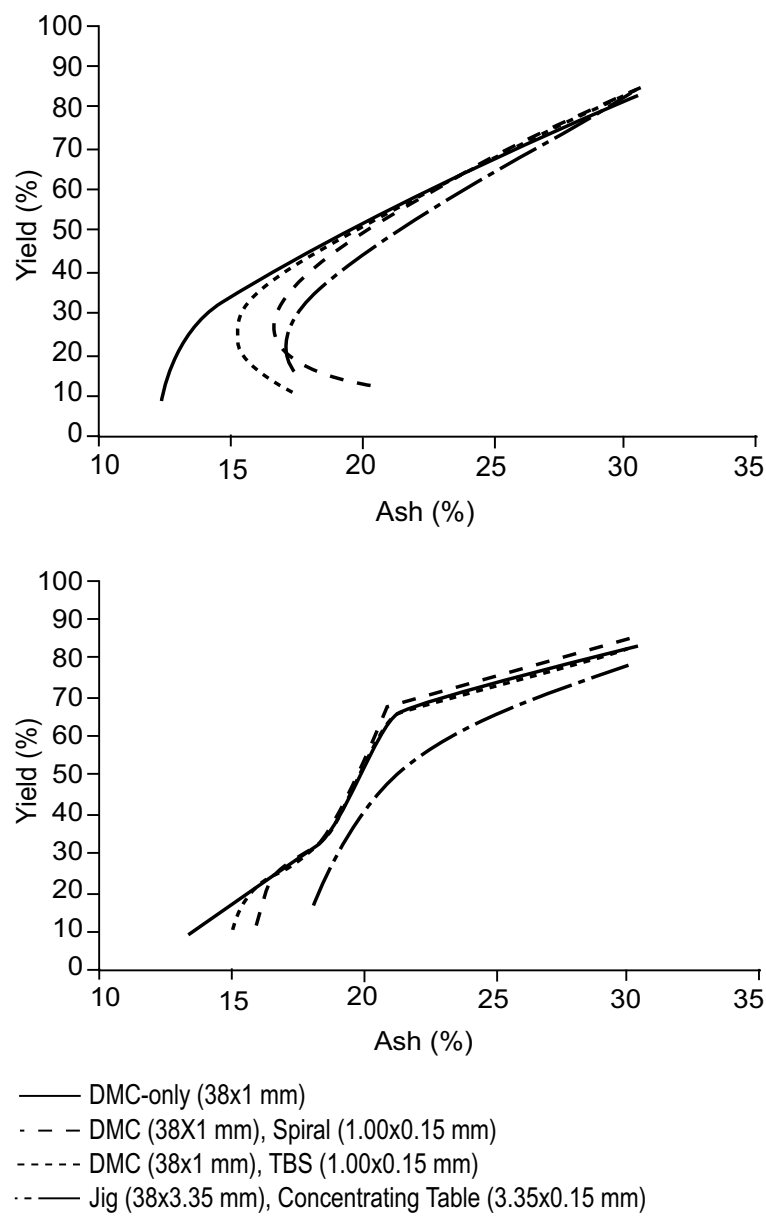

Fig. 11. Simulated yield-ash and yield-sulphur curves for the three circuits. 
sulphur for these circuits were plotted and are portrayed in Fig. 11.

Figure 11 shows that DMC-only circuit provides the highest yield with lower amounts of ash and sulphur in the clean coal at target ash content below $20 \%$, whereas above $20 \%$ ash, the circuit consisting of DMC and TBS is the better choice. At $16 \%$ limit ash, the maximum clean coal yield of $37.39 \%$ with sulphur content of $4.80 \%$ is achievable through coal preparation. To meet the sulphur limit of $1.0 \%$, blending of clean coal with low sulphur imported coal would be required.

Above $20 \%$ target ash content, the difference between the predicted yields provided by dense-medium and water-based circuits becomes less than 5\% which further decreases at higher values of target ash. Since, the capital and operating costs of water-based circuits is less than dense medium circuits, the economics may favour water-based circuit over dense medium circuits above $20 \%$ target ash content. Therefore, the economic analysis would be required before choosing the best circuit for cleaning Khokhar Bala coal.

\section{Conclusion}

Particle distribution data for size, density and floatability was established for Khokhar-Bala, Punjab coal. More than $93 \%$ of Khokhar-Bala coal is constituted by +1.00 $\mathrm{mm}$ particles. Overall, Khokhar-Bala coal is difficult to wash. The washing characteristics improve with decreasing particle size. The ultrafine fraction of Khokhar Bala coal exhibits poor flotation response. The $16 \%$ ash limit required by cement industry of Punjab can be achieved with reasonable clean coal yield. However, the sulphur contents could not be reduced below $1.0 \%$ limit. The dense-medium cyclone treating $+1.00 \mathrm{~mm}$ coal particles will be the most suitable choice for treating Khokhar-Bala coal below target ash content of $20 \%$. Above $20 \%$ ash, the combination of dense medium cyclone and teeter-bed separator will be a better option.

Conflict of Interest. The authors declare no conflict of interest.

\section{References}

Ali, Z. 2012. Identification of Improved Strategies for Processing Fine Coal, Bulletin 2078-B, Virginia Polytechnic Institute and State University, Virginia, USA.

Bergh, J.P., Falcon, R.M.S., Falcon, L.M., 2013. Techno- economic impact of optimized low-grade thermal coal export production through beneficiation modelling. The Journal of South African Institute of Mining and Metallurgy, 113: 817-824.

Bird, B.M. 1931. Interpretation of float-and-sink data, $3^{\text {rd }}$ International Conference on Bituminous Coal. Carnegie Institute of Technology, Pittsburgh, USA, $722 \mathrm{pp}$.

Bybell, L.M., Self-Trail, J.M. 2007. Calcareous Nannofossils from Paleogene Deposits in the Salt Range, Punjab, Northern Pakistan.

Gupta, A., Yan, D.S., 2006. Mineral Processing Design and Operation. eBookISBN:9780444516367, Elsevier, The Netherlands.

Hand, P.E., Wiseman, D.M. 2008. Combined coal and medium circuit simulation for design and optimisation. In: $12^{\text {th }}$ Australian Coal Preparation Conference and Exhibition, Mathewson, D. J. (editor), Darling Harbour, New South Wales, Australia.

Huang, Z., Mohanty, M., Sevim, H., Mahajan, A., Arnold, B. 2008. Techno-economic analysis of coal preparation plant design using siu-sim simulator. International Journal of Coal Preparation and Utilization, 28: 15-32.

King, R.P. 1999. Practical optimization strategies for coal-washing plants. Coal Preparation, 20: 13-34.

Lin, C.L., Parga, J.R., Drelich, J., Miller, J.D. 1999. Characterization of washability of some Mexican coals. Coal Preparation, 20: 227-245.

Luttrell, G.H., Bethell, P., Honaker, R.Q. 2014. Designing and operating fine coal processing circuits to meet market specifications. International Journal of Coal Preparation and Utilization, 34: 172-183.

Meyers, R.A., Laskowski, J.S., Walters, A.D. 1992. Coal preparation. In: Encyclopedia of Physical Science and Technology, Meyers, R. A. (editor), Academic Press, Inc., San Diego, pp. 409-435.

Noble, A., Bratton, R., Luttrell, G.H., Wiseman, D. 2014. Solving process engineering and flowsheet design challenges with limn, Annual Meeting \& Exhibition. Society for Mining, Metallurgy and Exploration, pp. 352-358, Salt Lake City, Utah, USA.

Osborne, D. 2013. The Coal Handbook Toward Cleaner Production, vol. 1, edition 1, Woodhead Pubishing Limited, Philadelphia, USA.

Osborne, D.G., Gupta, S.K. 2013. 1-Industrial uses of coal. In: The Coal Handbook: Towards Cleaner 
Production. D. Osborne (editor), pp. 3-30, Woodhead Publishing.

Oteyaka, B., Yamik, A., Ucar, A., Sahbaz, O., Demir, U. 2008. The washability of lignites for clay removal. Energy Sources, Part A: Recovery, Utilization and Environmental Effects, 30: 797-808.

Scott, M., Radonich, A., Gort, S., Smallwood, C., Ryan, N., Garsteling, M. 2013. Coal Resources of the Salt Range and Trans Indus Range, Punjab. Mines and Mineral Department. Government of Punjab, Pakistan.

Shah, S.M.I. 2009. Stratigraphy of Pakistan. Geological Survey of Pakistan, Ministry of Petroleum and Natural Resources, vol. 22, Government of Pakistan.

Shahzad, M., Ali, Z., 2018a. Cleaning of Dalwal-Punjab coal by using shaking table. Pakistan Journal of Scientific and Industrial Research, Series A: Physical Sciences, 61A: 56-58.

Shahzad, M., Ali, Z. 2018b. Development of simple techniques for determining the extent of coal cleaning-part 2: Estimating coal washability characteristics and separator performance. International Journal of Coal Preparation and Utilization, 1-14.

Shahzad, M., Ali, Z. 2019. A simple and efficient process for small-scale cleaning of poorly liberated, difficultto-wash low-rank coal. Energy Sources, Part A: Recovery, Utilization, and Environmental Effects, $1-14$.

Shahzad, M., Ali, Z., Majeed, Y., Emad, Z., Aaqib, M., Adeel, B. 2016. Liberation studies of Padhrar coal by using fractionation method, XRD analysis and megascopic and microscopic techniques. Pakistan Journal of Scientific and Industrial
Research, Series A: Physical Sciences, 59: 90-95. Shahzad, M., Ali, Z., Siddique, A. 2017. Cleaning of Dulmial-Punjab coal by froth flotation. Pakistan Journal of Scientific and Industrial Research. Series A: Physical Sciences, 60: 169-171.

Shahzad, M., Iqbal, M.M., Hassan, S.A., Saqib, S., Waqas, M. 2014. An assessment of chemical properties and hardgrove grindability index of Punjab coal. Pakistan Journal of Scientific and Industrial Research, Series A: Physical Sciences, 57: 139-144.

Shahzad, M., Tariq, S.M., Iqbal, M.M., Arshad, S.M., Saqib, S. 2015. An assessment of cleaning amenability of salt range coal through physical cleaning methods. Pakistan Journal of Scientific and Industrial Research, Series A: Physical Sciences, 58: 74-78.

Sripriya, R., Banerjee, P.K., Soni, Baijal, A.D., Dutta, A., Rao, M.V.S., Chatterjee, S. 2007. Dense-medium cyclone: plant experience with high near-gravity material Indian coals. Coal Preparation, 27: 78106.

Ural, S. 2007. Quantification of crystalline (mineral) matter in some Turkish coals using interactive rietveld-based X-ray diffractometry. International Journal of Coal Geology, 71: 176-184.

Ward, C.R. 2002. Analysis and significance of mineral matter in coal seams. International Journal of Coal Geology, 50: 135-168.

Yaqun, H., Shan, L., Maixi, L., Yali, K., Huaiyu, L. 2002. A profit-oriented expert system for coal washery optimization. Coal Preparation, 22: 93107. 